\title{
Coronavirus: Ushering in a New Era
}

\author{
Vandana Gangadharan ${ }^{1}$, George Koshy ${ }^{2}$ \\ Journal of Medical Academics (2020): 10.5005/jp-journals-10070-0055
}

No one had ever perceived a pre- and a post-COVID era, but here we are. The spread of severe acute respiratory syndrome coronavirus 2 (SARS-CoV-2) has been overwhelmingly rapid taking on pandemic proportions in just a matter of weeks. A combined global thrust in the preparedness and response of the healthcare system is the need of the hour to combat this unprecedented challenge. Countries that have been affected maximally have valuable lessons to pass on to the world. Although the forceful containment measures implemented, especially in China, have reduced new cases drastically, this reduction is not the case in other countries. ${ }^{1}$ And India, despite its stringent measures, is now emerging at the forefront of having to face the deadly brunt of this tiny virus.

One of the primary targets of the coronavirus $(\mathrm{CoV})$ is the human respiratory system. Previous outbreaks of CoVs include the severe acute respiratory syndrome (SARS)-CoV and the Middle East respiratory syndrome (MERS)-CoV which have posed huge public health challenges. At the end of December 2019, a cluster of patients was admitted to hospitals and although initially diagnosed as pneumonia, no specific etiology could be ascertained. Epidemiological linkage to seafood and wet animal wholesale market in Wuhan, Hubei Province, China was established. ${ }^{2,3}$ As per Chinese authorities, on the initial investigation, the causative agent appeared to be a novel coronavirus (2019-nCoV), and other respiratory pathogens were unlikely to be behind this clustering. ${ }^{4}$ Laboratory confirmation was obtained by January 2, 2020. Out of the 41 admitted patients, less than half had underlying lifestyle diseases, such as, diabetes, hypertension, and cardiovascular disease. $^{5}$ On January 30, 2020, WHO tentatively named the virus 2019 novel coronavirus (2019-nCoV) and subsequently on February 11, 2020, renamed it coronavirus disease-2019 (COVID-19). By March 2020, it had spread across the globe involving more than a hundred countries. The first case in India was seen on the 30th of January in the Trissur district of Kerala. Today, India is one of the countries reeling under the effects of this unrelenting pandemic with more than 1,750,723 confirmed cases and 37,364 deaths (WHO Dashboard).

Many a theory, including conspiracy, has to abound with this pandemic. Initially, it was thought to be a zoonotic disease and an effort was made to ascertain the reservoir host or an intermediate carrier through which infection was transmitted to humans. Despite preliminary reports indicating two species of snakes that could be a possible reservoir of the COVID-19, it has remained elusive and to date, there has been no consistent evidence of CoV reservoirs other than mammals and birds. ${ }^{6,7}$ Many reports have suggested personto-person droplet infection to be the most likely route of spread of the COVID-19 infection. Case to point being the occurrence even within families and among people who did not visit the wet animal market in Wuhan. ${ }^{8,9}$ However, without conclusive evidence of droplet infection or spread of the infection through community transmission other modes remain a possibility and need to be further explored for any relevant prevention. Adding fuel to the fire

${ }^{1}$ Department of Pathology, Army College of Medical Sciences, Delhi Cantonment, New Delhi, India

${ }^{2}$ Department of Community Medicine, Army College of Medical Sciences, Delhi Cantonment, New Delhi, India

Corresponding Author: Vandana Gangadharan, Department of Pathology, Army College of Medical Sciences, Delhi Cantonment, New Delhi, India, Phone: +91 7674942635, e-mail: vandanagangadharan@ gmail.com

How to cite this article: Gangadharan V, Koshy G. Coronavirus: Ushering in a New Era. J Med Acad 2020;3(1):1-3.

Source of support: Nil

Conflict of interest: None

the debate has even led to the most powerful nations raising fingers at one another and inching closer to the brink of war both military and economic, it is a harsh reality which we cannot wish away.

Coronavirus is enveloped, positive-strand RNA viruses, that may be transmitted to humans from intermediate hosts (usually peridomestic mammals) with bats being the likely reservoir of most of them. Though CoV is known to cause several diseases in animals, SARS-CoV-2 is the seventh CoV known to infect humans and is phylogenetically closer to the SARS-CoV than to the MERS-CoV. The new CoV, 2019-nCoV belongs to beta coronaviruses based on sequence analysis, infects the upper and lower respiratory tract, and can cause pneumonia in humans. It presents with symptoms that are milder than both SARS and MERS but transmits from human-to-human faster than them. ${ }^{10}$ It has been suggested to interact with the same main host receptor, angiotensin-converting enzyme 2 (ACE2), as SARS-CoV with the help of the spike surface glycoprotein of the virus. ${ }^{6}$ Angiotensin-converting enzyme 2 is expressed abundantly in various cells in the human body including the type Il alveolar cells of the lungs. However, the unequal response of various organs to the virus suggests other mechanisms at play. The main pathogenesis of COVID-19 infection as a respiratory system targeting virus is severe pneumonia, RNAemia, combined with ground-glass opacities on CT scan imaging, and acute cardiac injury. ${ }^{5}$ Patients infected with COVID-19 showed higher leukocyte numbers, abnormal respiratory findings, and increased levels of plasma proinflammatory cytokines. Dynamically monitoring hematological and coagulation parameters, such as, neutrophil-tolymphocyte ratio, platelet count, D-dimer, and prothrombin time might provide a reliable and convenient method for classifying and predicting the severity and outcomes of patients with COVID-19. The sepsis-induced coagulopathy (SIC) scoring system might be a useful tool to assess and manage critically ill patients. ${ }^{11}$

The symptoms of COVID-19 infection appear after an incubation period of approximately 5.2 days. ${ }^{12}$ The period from the onset of COVID-19 symptoms to death ranged from 6 to 41 days with a median of 14 days. ${ }^{13}$ This period is dependent on the age of the patient and the status of the patient's immune system. It is shorter

(c) The Author(s). 2020 Open Access This article is distributed under the terms of the Creative Commons Attribution 4.0 International License (https://creativecommons. org/licenses/by-nc/4.0/), which permits unrestricted use, distribution, and non-commercial reproduction in any medium, provided you give appropriate credit to the original author(s) and the source, provide a link to the Creative Commons license, and indicate if changes were made. The Creative Commons Public Domain Dedication waiver (http://creativecommons.org/publicdomain/zero/1.0/) applies to the data made available in this article, unless otherwise stated. 
among patients $>70$ years compared with those under the age of $70 .{ }^{14}$ The most common symptoms at the onset of COVID-19 illness are fever, cough, and fatigue, while other symptoms include sputum production, headache, hemoptysis, diarrhea, dyspnea, and lymphopenia. $8,13,15$ Mohan et al. in his study at a tertiary care center in North India revealed that a significant proportion of their patients (44.4\%) were asymptomatic at admission, and remained so throughout the hospital course. This may be a cause of concern as these asymptomatic patients are potential carriers or transmitters of infection in the community. Most symptomatic patients in the study presented with mild respiratory symptoms, such as, nasal symptoms, throat irritation, and cough, which differ from the reported symptoms in other studies. In this study, fever was present in only $17 \%$ of patients, which was far less compared to other reports across the globe, including the Chinese cohort in whom $44 \%$ had a fever at the time of presentation and $88 \%$ developed a fever during the hospital stay. Thus, overemphasis on fever as a predominant symptom may lead to several cases being missed. ${ }^{16}$ Thus, the varied symptomatic presentation and resemblance to other viral infections make the suspicion and detection of COVID-19 more challenging especially in a country like ours facing a resource crunch for quality detection.

The rapid and accurate laboratory diagnosis forms the cornerstone to treat the infection and halt the transmission. Reverse transcription polymerase chain reaction (RT-PCR) is the gold standard test recommended by WHO as well as ICMR for the confirmation of SARS-CoV-2. The mismatch in primers, probes, and target sequences may be a setback. Serological tests for the detection of SARS-CoV-2 IgG and IgM antibodies may supplement molecular diagnostic methods. However, the requirement of seroconversion and the inability to detect early infection is a concern. The use of rapid antigen-based assay has recently received approval and an advisory for its use has been released. It is a point of care test recommended for use in containment zones and healthcare settings.

No single measure is perhaps sufficient in combating this scrooge and a multipronged strategy would be most effective. All-out efforts should be made in preserving the most susceptible at the extremes of the age spectrum with special emphasis to safeguard and protect pregnant women and other vulnerable populations. The fight needs to be sustained by ensuring the care of the caregivers and other frontline workers. Epidemiological variations in COVID-19 infection should be monitored taking into account potential routes of transmission and subclinical infection. In addition, the adaptation, evolution, and antigenic variation of the virus among humans and possible intermediate animals and reservoirs should be constantly monitored. Some questions remain unanswered as to whether the number of cases is a mere reflection of the numbers tested and fluctuating as per testing policy. Standardized tests with transparent results may be the only way forward if we are to stop this juggernaut. Rothan and Byrareddy have raised these issues and others such as why very few pediatric cases have so far been reported; is this due to a lack of testing or a true lack of infection/susceptibility? Of the ones that have so far been tested, how many have developed the severe disease, and how many were tested positive but showed no clinical sign of disease? Some basic questions would provide a framework for which more specific and detailed public health measures can be implemented. ${ }^{17}$

One of the measures which has been extensively resorted to by governments globally including India has been nationwide lockdown restricting the movement of the population altogether hoping to curtail the infection and flatten the curve of this deadly virus. Of course, there would be a price to pay as evident from the effects seen on human behavior with the majority of the population experiencing negative psychosocial changes in one form or the other. An overall impact of overthinking and anxiety are inevitable consequences. ${ }^{18}$ In addition, loss of livelihood, the uncertainty of jobs, migration, and social alienation have added to the woes of the community sparing none and are perhaps just the tip of the iceberg.

From the beginning of this pandemic, another issue that has remained in the gray zone has been the use of masks, with WHO having to change its stance more than once on the issue. While dealing with a pathogen as deadly and contagious as the CoV SARSCoV-2, it is paramount that health workers use PPE to safeguard themselves. Sadly, these supplies are getting exhausted exposing health workers to occupational infection. ${ }^{19}$ Policies of health organizations for healthcare workers are inconsistent, with even countries like the US backtracking on their advisories. Community mask use by well people could be beneficial, particularly for COVID-19, where transmission may be presymptomatic. The studies of masks as source control also suggest a benefit and may be important during the COVID-19 pandemic in universal community face mask use as well as in healthcare settings. ${ }^{20}$

Current policies of at least $1 \mathrm{~m}$ physical distancing are associated with a large reduction in infection, and distances of $2 \mathrm{~m}$ might be more effective. These data also suggest that wearing face masks protects people (both healthcare workers and the general public) against infection by these CoVs, and that eye protection may provide additional benefit. Hand washing and hygiene have been reiterated a myriad number of times since the very beginning of this pandemic. However, none of these interventions afforded complete protection from infection, and their optimum role might need a risk assessment and several contextual considerations. Current evidence suggests that SARS-CoV-2 mainly spreads through large droplets and contact, the role of aerosol remains debatable. ${ }^{21}$ And a question that may have to be addressed in a country like ours is whether mask hygiene can be ensured where basic hygiene itself is questionable and whether the term social distancing will get a room in our exploding population.

Although the world awaits with bated breath for a breakthrough of an effective vaccine, it is unlikely that we would be seeing the last of this bane shortly. To date, there are no specific antiviral treatments or vaccines for SARS-CoV-2, and the mainstay of clinical treatment of COVID-19 has been a support and palliative care. We must develop a safe and effective vaccine sooner than later. ${ }^{22}$ Given the high rate of transmission of this virus between humans and its pandemics, it is important to identify the basis of its replication, structure, and pathogenicity for discovering a way to the special treatment or prevention. The high similarity of the virus to its families is a very big plus in finding the magic cure to this bane. Differences in the length of the spike as it is longer in COVID-19 are likely to play an important role in the pathogenesis and treatment of this virus. However, identifying the specific molecular details of the virus helps achieve treatment goals. ${ }^{23}$

Every passing year witnesses a steady climb in the prevalence of chronic diseases, and specific public health vaccination interventions may be the only shield for people with chronic diseases affected by an infection like SARS-CoV-2 and other respiratory viruses. ${ }^{24}$

We are likely to have a long and drawn battle with a virus that has proven hardy, climate-resistant, extremely infectious, and 
lethal. And perhaps we can hope and pray that there is indeed a post-COVID era.

\section{References}

1. Remuzzi A, Remuzzi G. COVID-19 and Italy: what next? Lancet 2020;395(10231):1225-1228. DOI: 10.1016/S0140-6736(20)30627-9.

2. Bogoch II, Watts A, Thomas-Bachli A, et al. Pneumonia of unknown aetiology in Wuhan, China: potential for international spread via commercial air travel. J Travel Med 2020;27(2):taaa008. DOI: 10.1093/ $\mathrm{jtm} / \mathrm{taaa008.}$

3. Lu H, Stratton CW, Tang YW. Outbreak of pneumonia of unknown etiology in Wuhan, China: the mystery and the miracle. J Med Virol 2020;92(4):401-402. DOI: 10.1002/jmv.25678.

4. Du Toit A. Outbreak of a novel coronavirus. Nat Rev Microbiol 2020;18(3):123. DOI: 10.1038/s41579-020-0332-0.

5. Huang C, Wang Y, Li X, et al. Clinical features of patients infected with 2019 novel coronavirus in Wuhan, China. Lancet 2020;395(10223):497506. DOI: 10.1016/S0140-6736(20)30183-5.

6. Bassetti M, Vena A, Giacobbe DR. The novel Chinese coronavirus (2019-nCoV) infections: challenges for fighting the storm. Eur J Clin Invest 2020;50(3):e13209. DOI: 10.1111/eci.13209.

7. Ji W, Wang W, Zhao X, et al. Cross-species transmission of the newly identified coronavirus 2019-nCoV. J Med Virol 2020;92(4):433-440. DOI: 10.1002/jmv.25682.

8. Carlos WG, Dela Cruz CS, Cao B, et al. Novel Wuhan (2019-nCoV) coronavirus. Am J Respir Crit Care Med 2020;201(4):P7-P8. DOI: 10.1164/rccm.2014P7.

9. Wu P, Hao X, Lau EHY, et al. Real-time tentative assessment of the epidemiological characteristics of novel coronavirus infections in Wuhan, China, as at 22 January 2020. Euro Surveill 2020;25(3):2000044. DOI: 10.2807/1560-7917.ES.2020.25.3.2000044.

10. Chen Y, Liu Q, Guo D. Emerging coronaviruses: genome structure, replication, and pathogenesis. J Med Virol 2020;92(4):418-423. DOI: 10.1002/jmv.25681.

11. Liao D, Zhou F, Luo L, et al. Haematological characteristics and risk factors in the classification and prognosis evaluation of COVID-19: a retrospective cohort study. Lancet Haematol 2020;7(9):E671-E678. DOI: https://doi.org/10.1016/ S2352-3026(20)30217-9.

12. Li Q, Guan X, Wu P, et al. Early transmission dynamics in Wuhan, China, of novel coronavirus-infected pneumonia. N Engl J Med 2020;382(13):1199-1207. DOI: 10.1056/NEJMoa2001316.
13. Wang W, Tang J, Wei F. Updated understanding of the outbreak of 2019 novel coronavirus (2019-nCoV) in Wuhan, China. J Med Virol 2020;92(4):441-447. DOI: 10.1002/jmv.25689.

14. Sahraei Z, Shabani M, Shokouhi S, et al. Aminoquinolines against coronavirus disease 2019 (COVID-19): chloroquine or hydroxychloroquine. Int J Antimicrob Agents 2020;55(4):105945. DOI: 10.1016/j.ijantimicag.2020.105945.

15. Ren LL, Wang YM, Wu ZQ, et al. Identification of a novel coronavirus causing severe pneumonia in human: a descriptive study. Chin Med J (Engl) 2020;133(9):1015-1024. DOI: 10.1097/CM9.

16. Mohan A, Tiwari P, Bhatnagar S, et al. Clinico-demographic profile \& hospital outcomes of COVID-19 patients admitted at a tertiary care centre in north India. Indian J Med Res 2020;152(1 \& 2):61-69. DOI: 10.4103/ijmr.IJMR_1788_20.

17. Rothan HA, Byrareddy SN. The epidemiology and pathogenesis of coronavirus disease (COVID-19) outbreak. J Autoimmun 2020;109:102433. DOI: 10.1016/j.jaut.2020.102433.

18. Kumar M, Dwivedi S. Impact of coronavirus-imposed lockdown on Indian population and their habits. Int J Sci Health Res 2020;5(2): 88-97.

19. Ippolito M, Vitale F, Accurso G, et al. Medical masks and respirators for the protection of healthcare workers from SARS-CoV-2 and other viruses. Pulmonology 2020;26(4):204-212. DOI: 10.1016/j. pulmoe.2020.04.009.

20. Maclntyre CR, Chughtai AA. A rapid systematic review of the efficacy of face masks and respirators against coronaviruses and other respiratory transmissible viruses for the community, healthcare workers and sick patients. Int J Nurs Stud 2020;108:103629. DOI: 10.1016/j.ijnurstu.2020.103629.

21. Chu DK, Akl EA, Duda S, et al. Physical distancing, face masks, and eye protection to prevent person-to-person transmission of SARS-CoV-2 and COVID-19: a systematic review and meta-analysis. Lancet 2020 395(10242):1973-1987. DOI: 10.1016/S0140-6736(20)31142-9.

22. Wang L, Wang Y, Ye D, et al. A review of the 2019 novel coronavirus (COVID-19) based on current evidence. Int J Antimicrob Agents 2020;55(6):105948. DOI: 10.1016/j.ijantimicag.2020.105948.

23. Mousavizadeh L, Ghasemi S. Genotype and phenotype of COVID-19: their roles in pathogenesis. J Microbiol Immunol Infect 2020. S16841182(20)30082-7 10.1016/j.jmii.2020.03.022.

24. Yang J, Zheng Y, Gou X, et al. Prevalence of comorbidities and its effects in patients infected with SARS-CoV-2: a systematic review and meta-analysis. Int J Infect Dis 2020;94:91-95. DOI: 10.1016/ j.ijid.2020.03.017. 